\title{
Multi objective Distributed Generators and D-STATCOM sitting and sizing by Modified Particle Swarm Optimization
}

\author{
G. Balakrishna ${ }^{1}$, Ch. Sai Babu ${ }^{2}$ \\ Associate Professor, Department of EEE, Intell Engineering Collge, Anantapur(AP), India ${ }^{1}$ \\ Professor, Department of EEE, JNTU College of Engineering, Kakinada(AP), India ${ }^{2}$
}

\begin{abstract}
This paper presents an algorithm based on Multi-objective modified Particle Swarm Optimization (MOMPSO) for determining optimal locations and optimal sizes of distributed generators and D-STATCOM units simultaneously. The problem has been solved by considering multiple objective functions of minimization of power loss, minimization of cost function and minimization of deviation of bus voltage. Sensitivity analysis is used to identify the candidate locations for installing DG and D-STATCOM units. The MOMPSO algorithm is used to find the optimal size of these units by considering the minimization of objective function subjected to practical constraints. The proposed algorithm has been tested on IEEE-33 and IEEE-69 test systems and results are presented.
\end{abstract}

Keywords: Distributed Generators (DGs), D-STATCOM, Multi objective function, modified particle swarm optimization, Sensitivity analysis.

\section{INTRODUCTION}

The distributed generators are considered as small scale electrical power generators, which generates active and reactive power and are going to be installed in the distribution systems itself where actually the need of electrical power. The addition of DGs in the distribution system relieves the generating stations and transmission and distributions systems from being additional electrical power because of load growth. Installing DG units helps to reduce the green house gas effects, improves the energy security, reduces the losses, and also improves the reliability and power quality [1]. The amount of power loss reduction is very much sensitive to the location and size of DGs. Therefore these loss can be minimized and better voltage profile can be obtained [2,3] by installing DGs which are operated with their optimal size.

Reactive power flow also plays very important role on portion of total power loss. The reactive power flow in the distribution system can also be controlled by connecting capacitors. The optimal allocation of shunt capacitor banks deals with determination of optimal locations, their sizes, type and number of capacitors so as to achieve maximum benefits [4]. In addition to the DG units, recently many researches [5-9] have dealt with the objective function of decreasing the loss and capacitor cost with proper capacitor placement. Distribution STATic Compensator (DSTATCOM) is the latest technology that can be connected in the distribution system to provide local reactive power generation. The connection of DSTATCOM in the distribution system regulates the bus voltage by providing the required amount of reactive power. Voltage source converter connected in parallel known as DSTATCOM can fix the power quality problems such as unbalanced nature of loads, voltage sag, fluctuation of voltage [10].

The process and concept of replacing the shunt capacitor

with DSTATCOM is discussed in [11]. DSTATCOM is a power electronic based synchronous voltage generator which is capable of providing quick and uninterrupted lagging and leading reactive power supply.

The optimal location and optimal size of DG units as well as DSTATCOM in distribution systems reduces the total power loss with power quality improvement. In this work real power loss is reduced by connecting DG units and reactive power compensation is provided by connecting DSTATCOM. The optimal locations of DG units and DSTATCOM are fixed according to sensitivity analysis.

In this paper, modified particle swarm optimization technique is proposed as methodology for solving the optimal sizing of DG units and DSTATCOM units by considering the multiple objectives such as minimization of power loss, cost function and deviation of bus voltage subjected to a set of practical constraints. The results obtained through the approach are presented and analysed.

\section{MODIFIED PARTICLE SWARM OPTIMIZATION (MPSO)}

In general for basic PSO, the velocity update equation of an element of any particle is defined as

$$
\begin{aligned}
& V_{i d}^{k+1}=\omega \cdot V_{i d}^{k}+c 1_{\text {.rand }} *\left(\text { Pbest }_{i d}-S_{i d}^{k}\right) \\
& +c 2_{\text {.rand }}^{k} *\left(\text { Gbest }{ }_{i d}-S_{i d}^{k}\right)
\end{aligned}
$$

This above velocity update equation has three components:

i) The first component is referred to "Inertia" or "Momentum". It represents the tendency of the particle to continue in the same direction it has been traveling. This component can be scaled by a constant or dynamically changing in the case of modified PSO.

ii) The second component represents local attraction 
towards the best position of a given particle whose corresponding fitness value is called the particles best $\left(\mathrm{P}_{\text {best }}\right)$ scaled by a random weight factor $\left(\mathrm{C}_{1}\right.$, randl $)$. This component is referred as "Memory" or "Self knowledge".

iii) The third component represents attraction towards the best position of any particle whose corresponding fitness value is called global best $\left(\mathrm{G}_{\text {best }}\right)$ scaled by another random weight factor $\left(C_{2}\right.$, rand2). This component is referred to "cooperation" "social knowledge", "group knowledge" or "shared information".

But in modified PSO in addition to the particles with best solution, particles with worst solution are also considered and the velocity update equation can be modified as

$$
V_{i d}^{k+1}=\left\{\begin{array}{l}
\omega . V_{i d}^{k}+c 1 \times r 1 \times k 1 \times\left(\text { Pbest }_{i d}-S_{i d}^{k}\right) \\
+c 2 \times r 2 \times k 2 \times\left(\text { Gbest }_{i d}-S_{i d}^{k}\right) \\
+c 3 \times r 3 \times k 3 \times\left(\text { Pworst }_{i d}-S_{i d}^{k}\right) \\
+c 4 \times r 4 \times k 4 \times\left(\text { Gworst }_{i d}-S_{i d}^{k}\right)
\end{array}\right]
$$

Where, C1 and C3 are the cognitive acceleration coefficients, $\mathrm{C} 2$ and $\mathrm{C} 4$ are the social acceleration coefficients, Gbest is the global best of the entire swarm, Gworst is the global worst of the entire swarm, K is the previous iteration number, $\mathrm{K}+1$ is the current iteration number, $\mathrm{K}=[\mathrm{k} 1, \mathrm{k} 2, \mathrm{k} 3, \mathrm{k} 4]$ is switch matrix and its value is $[1,1,0,0]$ for best particles and $[0,0,1,1]$ for worst particles, Pbest is the particle's best, Pworst is the particle's worst, r1,r2,r3 and r4 are the random numbers between 0 to $1, S_{i d}^{k}$ is the position of $\mathrm{i}^{\text {th }}$ particle, $V_{i d}^{k}$ is the velocity of $i^{\text {th }}$ particle.

The position of any element in $(\mathrm{k}+1)^{\text {th }}$ iteration can be modified according to

$$
S_{i d}^{k+1}=S_{i d}^{k}+V_{i d}^{k+1}
$$

$\mathrm{i}=1,2, \ldots \ldots, \mathrm{n} . \quad \mathrm{d}=1,2, \ldots ., \mathrm{m}$.

Where $s^{k}$ is current searching point, $s^{k+1}$ is modified searching point, $v^{k}$ is current velocity, $v^{k+1}$ is modified velocity of agent $\mathrm{i}, v_{\text {pbest }}$ is velocity based on Pbest, $v_{\text {gbest }}$ is velocity based on gbest, $\mathrm{n}$ is number of particles in a group, $m$ is the number of members in a particles, pbest is pbest of agent $\mathrm{i}$, gbest is gbest of the group, $\omega_{i}$ is weight function for velocity of agent $\mathrm{i}, c_{i}$ is weight coefficient for each term.

The following weight function is used:

$$
\omega_{i}=\omega_{\max }-\frac{\omega_{\max }-\omega_{\min }}{k_{\max }} \times k
$$

Where, $\omega_{\min }$ and $\omega_{\max }$ are the minimum and maximum weights respectively. $\mathrm{k}$ and $k_{\max }$ are the current and maximum iteration.

\subsection{Generation of a particle:}

Initialization: Following algorithm is used to generate a particle consisting of real and reactive power outputs of DG units and reactive power rating of D-STATCOM unit Step 1: Set i=1

Step 2: Select the active power rating of first DG within the active power generation limits of the respective DG
Step 3: Repeat step 2 for all DG units

Step 4: Select the reactive power rating (if any) of first DG within the reactive power generation limits of the respective DG

Step 5: Repeat step 4 for all DG units

Step 6: Select the reactive power rating of D-STATCOM rating within the limits of its rating

Step 7: increment the particle number i.e., $\quad i=i+1$

Step 8: If all particles are generated stop the initialization process, otherwise go to step 2 .

The individual particle as created above is taken as list the initial optimal sizes.

\subsection{Algorithm for optimal sizing}

The algorithm to find the optimal sizes of DGs is:

Step 1: Read the line and load data of the system and DG units data

Step 2: Calculate the power loss using the distribution load flow based on backward and forward sweep algorithm for the original network

Step 3: Initialize the particles according to the algorithm given above

Step 4: For each particle find the objective function according to equation (8)

Step 5: If the objective function of each particle is better than the previous experience, then update its $P_{\text {best }}$

Step 6: Find the $\mathrm{G}_{\text {best }}$ by considering the fitness value of all the particles

Step 7: Find the velocity of each particle according to the equation (2)

Step 8: Update the velocity and position by using equations (3)

Step 9: If the iteration number reaches the maximum limit print the results,

Step 10: Otherwise set increase iteration count by one and go back to step 4.

Finally the optimal size (Real and reactive power outputs) of DGs can be observed from final $G_{\text {best. }}$

\section{PROBLEM FORMULATION}

The main goal of the proposed algorithm is to determine the optimal location and optimal size of the DG and DSTATCOM units by minimizing the different objective functions. In this section three objective functions and their practical constraints is presented.

Loss sensitive factors are used to decide the optimal locations of DG and DSTATCOM units and their size is obtained by solving multi-objective function with modified particle swarm optimization subjected to practical constraints.

\subsection{Objective Functions:}

3.1.1 Minimization of real power loss:

Minimization of power loss is considered as first objective function for the placement of DG.

$$
f_{1}(x)=\operatorname{Min} \cdot \sum_{l=1}^{N_{l}}\left[\left|I_{l}\right|^{2} \times R_{l}\right]
$$

Where $I_{l}$ is the current through branch ' $l$ ' and $R_{l}$ is the resistance of branch ' $l$ '. 
3.1.2 Minimization of cost function

Minimization of cost of function is considered as second objective function for the placement of DG and it can be modeled as

$$
\begin{aligned}
& f_{2}(x)=\text { Minimizing } \quad \sum_{i=1}^{N_{D G}} C\left(D G_{i}\right)+ \\
& P_{\text {sub }} \times T \times \text { price }_{\text {sub }}+C\left(E_{L}\right)+\sum_{i=1}^{N_{D S}} C\left(D S_{i}\right)
\end{aligned}
$$

Where $N_{D G}$ is the number of dg units used, $C\left(D G_{i}\right)$ is the cost of energy generated by the $i^{\text {th }}$ DG units (\$) [13], $C\left(E_{L}\right)$ is the cost of energy loss, $P_{\text {sub }}$ is the real power at the substation bus $(\mathrm{kW})$, Price $_{\text {sub }}$ is the price of active power at substation in $(\$ / \mathrm{kWh}), \mathrm{T}$ is the time period in hours. The above cost function is calculated for 15 years.

3.1.3 Minimization of deviation of bus voltage (D.V.B) Minimization of deviation of bus voltages is considered as third objective function of reconfiguration problem.

$$
f_{2}(x)=\text { Minimizing } \sum_{i=1}^{N_{b}}\left|V_{r}-V_{i}\right|
$$

Where $\mathrm{Nb}$ is the number of buses or nodes, $\mathrm{V} i$ is the voltage magnitude at $i^{\text {th }}$ bus, $\mathrm{Vr}$ is the rated voltage magnitude at $i^{\text {th }}$ bus (1 p.u.)

\subsection{Constraints:}

The above multi-objective function is solved by onsidering a set of practical constraints.

\subsubsection{Voltage magnitude constraint:}

Voltage magnitude at each bus should be within the specified limits even after placing a DG i.e., it should be greater than $V_{\min }$ and less than $V_{\max }$ and is represented as

$$
V_{\min } \leq V_{j} \leq V_{\max }
$$

3.2.2 Feeder capability constraint:

The magnitude of the current through all the line sections should be within the tolerable limits of the respective section i.e.

$$
I_{k} \leq I_{k}^{\max }, k \in\{1,2,3 \ldots . . l\}
$$

Where $I_{k}^{\max }$ is maximum current capability of branch k

\subsubsection{Distributed generator constraint:}

If a DG unit is installed at bus ' $i$ ', its active and reactive power generations should be within the DG unit's capacity limits; otherwise these values should be equal to zero. Mathematically, this constraint can be developed as:

$$
\begin{gathered}
W_{i} \cdot P_{G, i}^{\min } \leq P_{G, i} \leq W_{i} \cdot P_{G, i}^{\max } \quad i \in N \quad \& \quad i \neq \text { Sub } \\
W_{i} \cdot Q_{G, i}^{\min } \leq Q_{G, i} \leq W_{i} \cdot Q_{G, i}^{\max } \quad i \in N \quad \& \quad i \neq \text { Sub }
\end{gathered}
$$

$W_{i}$ is a binary variable used to describe the installation of DG on bus ' $i$ '. When a DG unit is installed at bus ' $i$ ', $W_{i}$ $=1$ other wise $W_{i}=0$

\subsubsection{D-STATCOM constraints:}

If a DSTATCOM is installed at bus ' $i$ ', its reactive power generations should be within the range of its kVar. Mathematically this constraint can be represented as:

$$
W_{i} \cdot Q_{D S i}^{\min } \leq Q_{D S i} \leq W_{i} \cdot Q_{D S i}^{\max } i \in N_{b} \& i \neq S u b
$$

Finally multi-objective function can be developed as

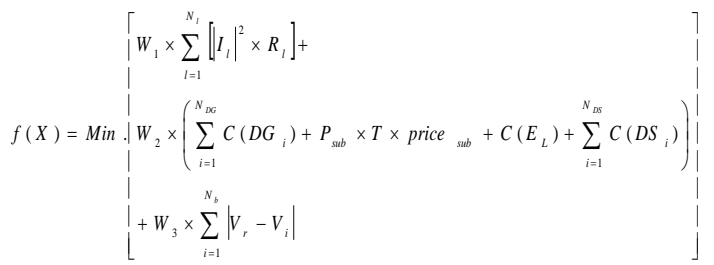

$W_{1}, W_{2}$ and $W_{3}$ are the weighing factors subjected to a condition that $\mathrm{W}_{1}+\mathrm{W}_{2}+\mathrm{W}_{3}=1$

\section{DISTRIBUTION STATIC COMPENSATOR (D-STATCOM)}

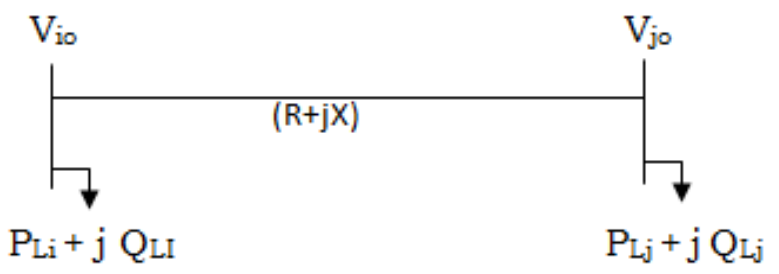

Fig. 1 Sample line section of a distribution system By considering the fig.1 the following relationship between voltage and current can be developed as

$$
V_{j o} \angle \alpha_{o}=V_{i o} \angle \delta_{o}-(R+j X) \times I_{L o} \angle \theta_{o}
$$

In the above equation

$V_{i o} \angle \delta_{o} \quad$ is the voltages at bus ' $i$ ' before connecting DSTATCOM, $V_{j o} \angle \alpha_{o}$ is the voltages at bus ' $j$ ' before connecting DSTATCOM, $(R+j X)$ is the impedance of the branch connected between buses ' $i$ ' and ' $j$ ', $I_{L o} \angle \theta_{o}$ is the current through the branch connected between buses ' $i$ ' and ' $j$ '

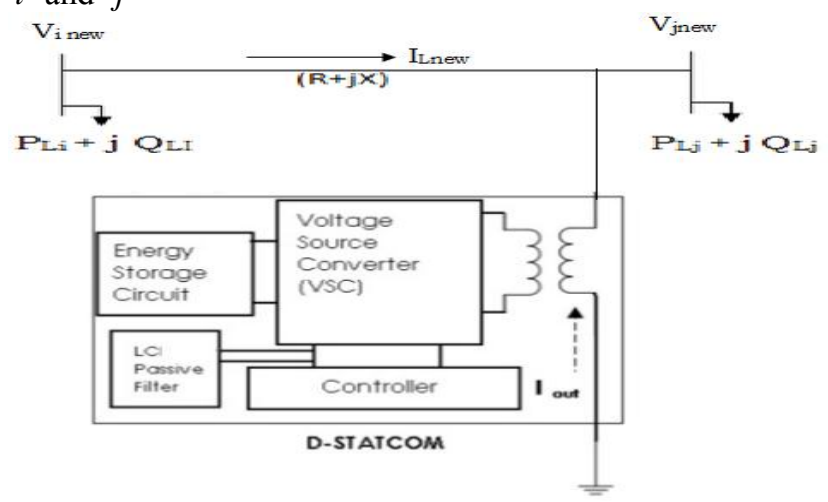

Fig.2 Distribution system connected with DSTATCOM

After connecting DSTATCOM as shown in fig.2, the voltage at bus ' $\mathrm{j}$ ' changes from its previous value $V_{j o} \angle \alpha_{o}$ to a new value $V_{\text {jnew }} \angle \alpha_{\text {new }}$ and is given by

$$
\begin{aligned}
& V_{\text {jnew }} \angle \alpha_{\text {new }}=V_{\text {io }} \angle \delta_{o}-(R+j X) \times I_{\text {Lnew }} \angle \theta_{\text {new }} \\
& -(R+j X) \times I_{D-\text { STATCOM }} \angle\left((\pi / 2)+\alpha_{\text {new }}\right)
\end{aligned}
$$


Where

$I_{D-\text { STAтсом }} \angle\left((\pi / 2)+\alpha_{\text {new }}\right)$ is the current injected by

D-STATCOM and $\alpha_{n e w}$ is the angle of corrected voltage, $V_{\text {jnew }} \angle \alpha_{\text {new }}$ is the voltage at bus ' $\mathrm{j}$ ' after connecting D-

STATCOM, $I_{\text {Lnew }} \angle \theta_{\text {new }}$ is the current through the branch after connecting D-STATCOM and is given by

$$
I_{\text {Lnew }} \angle \theta_{\text {new }}=I_{o L} \angle \theta_{o}+I_{D-\text { STATCOM }} \angle\left((\pi / 2)+\alpha_{\text {new }}\right) \ldots
$$

\section{RESULTS AND ANALYSIS}

The proposed MOMPSO is tested on two test systems viz., IEEE 33, IEEE 69 bus radial distribution systems and results are presented. For these test systems two cases are considered:

Case-1: Optimal sitting and sizing of DG units without DSTATCOM

Case-2: Optimal sitting and sizing of both DG units and DSTATCOM

Based on the sensitivity analysis, D-STATCOM is installed at bus 6 for IEEE-33 bus system and bus 61 for
IEEE-69 system. DG units are placed at bus numbers 11, 29 and 31 for IEEE-33 bus system and for IEEE-69 system bus numbers 60,63 and 62 are selected. To show the effect of distributed generator and D-STATCOM placement and its size, the single objective optimal placement of DG for power loss, cost function and deviation of bus voltage are tabulated in table 1. From these table it is observed that, due to the presence of both distributed generator and D-STATCOM units the values of objective functions are better when compared to the objective functions with D-STATCOM units only. Further it is also identified that, minimization of one of the objectives increases the values of other objective function values. For example, minimization of cost function increases the power loss and deviation of bus voltage.

It is also observed that, installing D-STATCOM units along with DG units reduces the losses, cost function and deviation of bus voltage. This is because, the addition DG units provides the real and reactive power injections into the system and D-STATCOM provides reactive power decreases the current through various line sections thereby reduces the power loss and decreases the cost and improves the voltage profile.

Table 1: Results of IEEE-33 bus system for single objective functions

\begin{tabular}{|c|c|c|c|c|c|c|c|c|}
\hline \multirow{2}{*}{ S.No. } & \multirow{2}{*}{$\begin{array}{c}\text { Control } \\
\text { Parameter }\end{array}$} & \multirow{2}{*}{$\begin{array}{c}\text { Original } \\
\text { System }\end{array}$} & \multicolumn{2}{|c|}{$\begin{array}{c}\text { Minimization of } \\
\text { power loss }\end{array}$} & \multicolumn{2}{c|}{$\begin{array}{c}\text { Minimization of } \\
\text { Cost function }\end{array}$} & \multicolumn{2}{c|}{$\begin{array}{c}\text { Minimization of } \\
\text { Deviation of bus voltage }\end{array}$} \\
\cline { 5 - 9 } & & Case-1 & Case-2 & Case-1 & Case-2 & Case-1 & Case-2 \\
\hline 1 & $\mathrm{P}_{\mathrm{DG} 1}(\mathrm{~kW})$ & - & - & 146.32 & - & 132.47 & - & 140.26 \\
\hline 2 & $\mathrm{P}_{\mathrm{DG} 2}(\mathrm{~kW})$ & - & - & 54.98 & - & 58.14 & - & 59.21 \\
\hline 3 & $\mathrm{P}_{\mathrm{DG} 3}(\mathrm{~kW})$ & - & - & 714.32 & - & 571.26 & - & 638.39 \\
\hline 4 & $\mathrm{Q}_{\mathrm{DG} 3}(\mathrm{~kW})$ & - & - & 451.32 & - & 474.11 & - & 521.21 \\
\hline 5 & $\mathrm{Q}_{\mathrm{DS} 1}(\mathrm{kVar})$ & - & 642.38 & 684.23 & 541.36 & 457.84 & 648.11 & 681.36 \\
\hline 6 & Losses $(\mathrm{kW})$ & 211.48 & 154.62 & 126.31 & 167.21 & 142.67 & 156.16 & 128.14 \\
\hline 7 & $\begin{array}{c}\text { Cost function } \\
\text { Million } \$)\end{array}$ & 31.4111 & 29.1465 & 27.6426 & 29.1145 & 27.4246 & 29.0942 & 27.7829 \\
\hline 8 & D.V.B & 1.806 & 0.926 & 0.821 & 0.932 & 0.842 & 0.916 & 0.811 \\
\hline
\end{tabular}

Table 2: Results of IEEE-33 bus system for two objective functions in three combinations for different weight factors

\begin{tabular}{|c|c|c|c|c|c|c|c|c|c|c|c|c|c|c|}
\hline \multirow[b]{3}{*}{$\begin{array}{l}\text { Set } \\
\text { No. }\end{array}$} & \multicolumn{2}{|c|}{$\begin{array}{l}\text { Weight } \\
\text { factors }\end{array}$} & \multicolumn{4}{|c|}{ Combination-1 } & \multicolumn{4}{|c|}{ Combination-2 } & \multicolumn{4}{|c|}{ Combination-3 } \\
\hline & \multirow[b]{2}{*}{ W1 } & \multirow[b]{2}{*}{ W2 } & \multicolumn{2}{|c|}{ Case-1 } & \multicolumn{2}{|c|}{ Case-2 } & \multicolumn{2}{|c|}{ Case-1 } & \multicolumn{2}{|c|}{ Case-2 } & \multicolumn{2}{|c|}{ Case-1 } & \multicolumn{2}{|c|}{ Case-2 } \\
\hline & & & $\begin{array}{l}\text { T.P.L } \\
(\mathrm{kW})\end{array}$ & $\begin{array}{c}\text { Cost } \\
\text { function } \\
\text { (Million } \\
\$ \text { ) }\end{array}$ & $\begin{array}{l}\text { T.P.L } \\
(\mathrm{kW})\end{array}$ & $\begin{array}{c}\text { Cost } \\
\text { function } \\
\text { (Million } \\
\$ \text { ) }\end{array}$ & $\begin{array}{c}\text { Cost } \\
\text { function } \\
\text { (Million } \\
\$)\end{array}$ & D.B.V & $\begin{array}{l}\text { Cost } \\
\text { function } \\
\text { (Million } \\
\$ \text { ) }\end{array}$ & D.B.V & $\begin{array}{l}\text { T.P.L } \\
(\mathrm{kW})\end{array}$ & D.B.V & $\begin{array}{l}\text { T.P.L } \\
(\mathrm{kW})\end{array}$ & D.B.V \\
\hline 1 & 0.1 & 0.9 & 147.38 & 29.1677 & 142.44 & 27.3272 & 29.9451 & 0.920 & 27.9951 & 0.813 & 146.77 & 0.918 & 141.37 & 0.812 \\
\hline 2 & 0.2 & 0.8 & 147.38 & 29.1677 & 142.44 & 27.3272 & 29.9451 & 0.920 & 27.9951 & 0.813 & 146.77 & 0.918 & 141.37 & 0.812 \\
\hline 3 & 0.3 & 0.7 & 142.66 & 29.2246 & 134.76 & 27.6456 & 29.6425 & 0.924 & 27.9504 & 0.827 & 142.41 & 0.925 & 135.17 & 0.825 \\
\hline 4 & 0.4 & 0.6 & 142.66 & 29.2246 & 134.76 & 27.6456 & 29.6425 & 0.924 & 27.9504 & 0.827 & 142.41 & 0.925 & 135.17 & 0.825 \\
\hline 5 & 0.5 & 0.5 & 139.24 & 29.3171 & 128.37 & 27.9478 & 29.4114 & 0.930 & 27.6466 & 0.834 & 139.01 & 0.925 & 127.91 & 0.833 \\
\hline 6 & 0.6 & 0.4 & 139.24 & 29.3171 & 128.37 & 27.9478 & 29.4114 & 0.930 & 27.6466 & 0.834 & 139.01 & 0.929 & 127.91 & 0.833 \\
\hline 7 & 0.7 & 0.3 & 136.55 & 29.9477 & 124.23 & 27.9949 & 29.4114 & 0.930 & 27.6466 & 0.834 & 139.01 & 0.929 & 123.74 & 0.842 \\
\hline 8 & 0.8 & 0.2 & 136.55 & 29.9477 & 124.23 & 27.9949 & 29.1549 & 0.935 & 27.3281 & 0.844 & 135.87 & 0.934 & 123.74 & 0.842 \\
\hline 9 & 0.9 & 0.1 & 136.55 & 29.9477 & 124.23 & 27.9949 & 29.1549 & 0.935 & 27.3281 & 0.844 & 135.87 & 0.934 & 123.74 & 0.842 \\
\hline
\end{tabular}


IARJSET

International Advanced Research Journal in Science, Engineering and Technology

Vol. 2, Issue 12, December 2015

Table 3: Results of IEEE-33 bus system for three objective functions for different weight factors

\begin{tabular}{|c|c|c|c|c|c|c|c|c|c|}
\hline \multirow{2}{*}{$\begin{array}{c}\text { S. } \\
\text { No. }\end{array}$} & \multicolumn{2}{|c|}{ Weight Factors } & \multicolumn{4}{c|}{ Case-1 } & \multicolumn{3}{c|}{ Case-2 } \\
\hline 1 & W1 & W2 & W3 & $\begin{array}{c}\text { T.P.L } \\
(\mathrm{kW})\end{array}$ & $\begin{array}{c}\text { Cost function } \\
(\text { Million \$) }\end{array}$ & D.B.V & $\begin{array}{c}\text { T.P.L } \\
(\mathrm{kW})\end{array}$ & $\begin{array}{c}\text { Cost function } \\
(\text { Million \$) }\end{array}$ & D.B.V \\
\hline 2 & 0.1 & 0.1 & 0.8 & 148.67 & 29.9481 & 0.9172 & 145.74 & 27.9994 & 0.8134 \\
\hline 3 & 0.8 & 0.1 & 0.1 & 148.67 & 29.1679 & 0.9330 & 145.74 & 27.3290 & 0.8416 \\
\hline 4 & 0.5 & 0.3 & 0.2 & 137.57 & 29.9481 & 0.9330 & 124.68 & 27.9994 & 0.8416 \\
\hline 5 & 0.5 & 0.2 & 0.3 & 139.21 & 29.5671 & 0.9301 & 134.79 & 27.5874 & 0.8344 \\
\hline 6 & 0.3 & 0.5 & 0.2 & 142.44 & 29.7749 & 0.9286 & 134.79 & 27.7142 & 0.8291 \\
\hline 7 & 0.3 & 0.2 & 0.5 & 142.44 & 29.7747 & 0.9301 & 137.22 & 27.4467 & 0.8344 \\
\hline 8 & 0.2 & 0.5 & 0.3 & 146.89 & 29.3456 & 0.9244 & 141.46 & 27.7142 & 0.8187 \\
\hline 9 & 0.2 & 0.3 & 0.5 & 146.89 & 29.5671 & 0.9245 & 143.27 & 27.4467 & 0.8291 \\
\hline
\end{tabular}
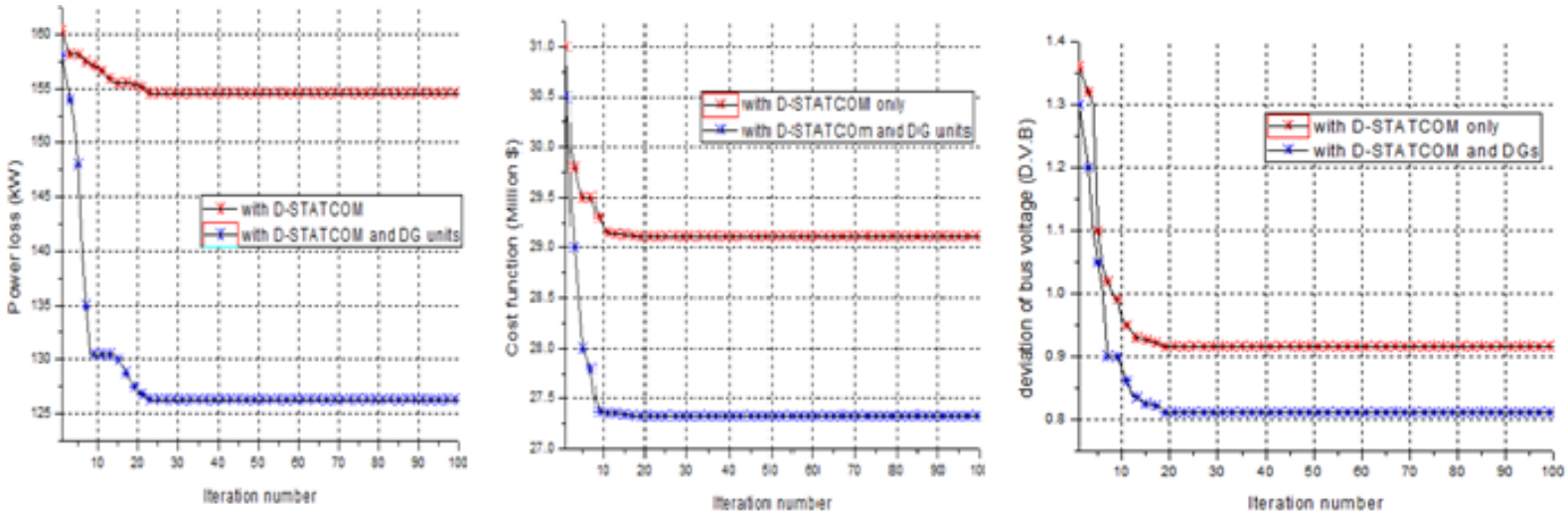

Fig. 3 Convergence characteristics of MPSO for IEEE-33 bus system Single objective of Minimization of power loss, minimization of cost function, minimization of D.V.B
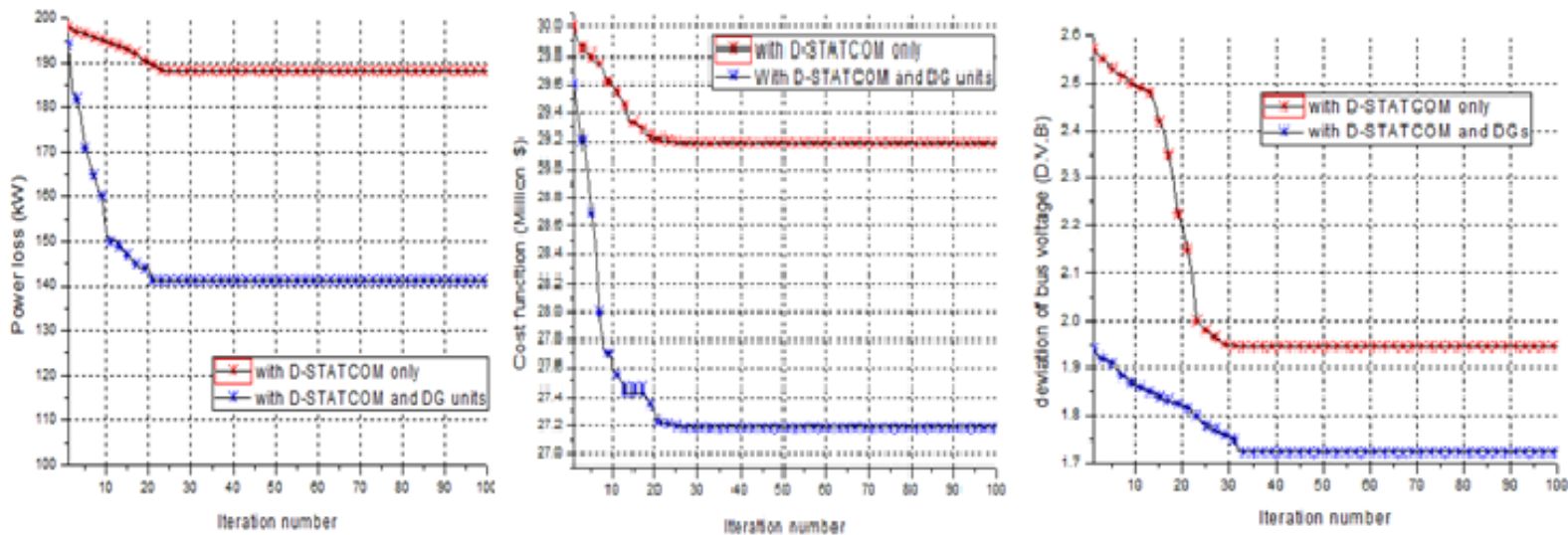

Fig. 4 Convergence characteristics of MPSO for IEEE-69 bus system Single objective of Minimization of power loss, minimization of cost function, minimization of D.V.B

Table 4: Results of IEEE-69 bus system for single objective functions

\begin{tabular}{|c|c|c|c|c|c|c|c|c|}
\hline \multirow{2}{*}{ S.No. } & \multirow{2}{*}{$\begin{array}{c}\text { Control } \\
\text { Parameter }\end{array}$} & \multirow{2}{*}{$\begin{array}{c}\text { Original } \\
\text { system }\end{array}$} & \multicolumn{2}{c|}{$\begin{array}{c}\text { Minimization of } \\
\text { power loss }\end{array}$} & \multicolumn{2}{c|}{$\begin{array}{c}\text { Minimization of } \\
\text { Cost function }\end{array}$} & \multicolumn{2}{c|}{$\begin{array}{c}\text { Minimization of } \\
\text { Deviation of bus voltage }\end{array}$} \\
\cline { 5 - 9 } & & Case-1 & Case-2 & Case-1 & Case-2 & Case-1 & Case-2 \\
\hline 1 & $\mathrm{P}_{\mathrm{DG} 1}(\mathrm{~kW})$ & - & - & 161.22 & - & 139.27 & - & 168.21 \\
\hline 2 & $\mathrm{P}_{\mathrm{DG} 2}(\mathrm{~kW})$ & - & - & 59.27 & - & 51.78 & - & 59.68 \\
\hline 3 & $\mathrm{P}_{\mathrm{DG} 3}(\mathrm{~kW})$ & - & - & 672.76 & - & 610.74 & - & 681.24 \\
\hline 4 & $\mathrm{Q}_{\mathrm{DG} 3}(\mathrm{~kW})$ & - & - & 581.22 & - & 435.39 & - & 501.22 \\
\hline 5 & $\mathrm{Q}_{\mathrm{DS} 1}(\mathrm{kVar})$ & - & 651.33 & 711.38 & 578.32 & 492.34 & 721.44 & 754.18 \\
\hline 6 & Losses $(\mathrm{kW})$ & 224.68 & 188.21 & 141.32 & 192.47 & 149.47 & 191.32 & 143.39 \\
\hline 7 & $\begin{array}{c}\text { Cost function } \\
\text { Million } \$)\end{array}$ & 30.7053 & 29.9416 & 27.3088 & 29.8816 & 27.2849 & 29.9468 & 27.3148 \\
\hline 8 & D.V.B & 3.8377 & 1.9681 & 1.7444 & 1.9805 & 1.7892 & 1.9465 & 1.7233 \\
\hline
\end{tabular}


International Advanced Research Journal in Science, Engineering and Technology

Vol. 2, Issue 12, December 2015

Table 5: Results of IEEE-69 bus system for two objective functions in three combinations with different weight factors

\begin{tabular}{|c|c|c|c|c|c|c|c|c|c|c|c|c|c|c|}
\hline \multirow{3}{*}{$\begin{array}{l}\text { Set } \\
\text { No. }\end{array}$} & \multicolumn{2}{|c|}{$\begin{array}{l}\text { Weight } \\
\text { factors }\end{array}$} & \multicolumn{4}{|c|}{ Combination-1 } & \multicolumn{4}{|c|}{ Combination-2 } & \multicolumn{4}{|c|}{ Combination-3 } \\
\hline & \multirow[b]{2}{*}{ W1 } & \multirow[b]{2}{*}{ W2 } & \multicolumn{2}{|c|}{ Case-1 } & \multicolumn{2}{|c|}{ Case-2 } & \multicolumn{2}{|c|}{ Case-1 } & \multicolumn{2}{|c|}{ Case-2 } & \multicolumn{2}{|c|}{ Case-1 } & \multicolumn{2}{|c|}{ Case-2 } \\
\hline & & & $\begin{array}{l}\text { T.P.L } \\
(\mathrm{kW})\end{array}$ & $\begin{array}{c}\text { Cost } \\
\text { function } \\
\text { (Million } \\
\$ \text { ) }\end{array}$ & $\begin{array}{l}\text { T.P.L } \\
(\mathrm{kW})\end{array}$ & $\begin{array}{c}\text { Cost } \\
\text { function } \\
\text { (Million } \\
\$ \text { ) }\end{array}$ & $\begin{array}{c}\text { Cost } \\
\text { function } \\
\text { (Million } \\
\$ \text { ) }\end{array}$ & D.B.V & $\begin{array}{c}\text { Cost } \\
\text { function } \\
\text { (Million } \\
\$ \text { ) }\end{array}$ & D.B.V & $\begin{array}{l}\text { T.P.L } \\
(\mathrm{kW})\end{array}$ & D.B.V & $\begin{array}{l}\text { T.P.L } \\
(\mathrm{kW})\end{array}$ & D.B.V \\
\hline 1 & 0.1 & 0.9 & 192.44 & 29.2116 & 151.29 & 27.1844 & 30.0018 & 1.947 & 27.3158 & 1.724 & 191.26 & 1.982 & 148.38 & 1.722 \\
\hline 2 & 0.2 & 0.8 & 192.44 & 29.2116 & 151.29 & 27.1844 & 30.0018 & 1.947 & 27.3158 & 1.724 & 191.26 & 1.982 & 148.38 & 1.722 \\
\hline 3 & 0.3 & 0.7 & 189.49 & 29.3874 & 147.62 & 27.2578 & 30.0018 & 1.947 & 27.3158 & 1.724 & 188.69 & 1.978 & 145.29 & 1.746 \\
\hline 4 & 0.4 & 0.6 & 189.49 & 29.3874 & 147.62 & 22.2578 & 29.7456 & 1.958 & 27.2946 & 1.748 & 188.69 & 1.978 & 145.29 & 1.746 \\
\hline 5 & 0.5 & 0.5 & 184.38 & 29.5518 & 143.88 & 27.3124 & 29.7456 & 1.958 & 27.2946 & 1.748 & 188.69 & 1.957 & 145.29 & 1.746 \\
\hline 6 & 0.6 & 0.4 & 184.38 & 29.5518 & 143.88 & 27.3124 & 29.4416 & 1.969 & 27.2619 & 1.769 & 183.47 & 1.957 & 142.33 & 1.768 \\
\hline 7 & 0.7 & 0.3 & 184.38 & 29.5518 & 143.88 & 27.3124 & 29.4416 & 1.969 & 27.2619 & 1.769 & 183.47 & 1.957 & 142.33 & 1.768 \\
\hline 8 & 0.8 & 0.2 & 179.27 & 29.9924 & 141.11 & 27.3477 & 29.3118 & 1.982 & 27.1977 & 1.791 & 177.22 & 1.945 & 139.84 & 1.789 \\
\hline 9 & 0.9 & 0.1 & 179.27 & 29.9924 & 141.11 & 27.3477 & 29.3118 & 1.982 & 27.1977 & 1.791 & 177.22 & 1.945 & 139.84 & 1.789 \\
\hline
\end{tabular}

Table 6: Results of IEEE-69 bus system for three objective functions for different weight factors

\begin{tabular}{|c|c|c|c|c|c|c|c|c|c|}
\hline \multirow{2}{*}{ S. No. } & \multicolumn{3}{|c|}{ Weight Factors } & \multicolumn{3}{|c|}{$\begin{array}{c}\text { (Case-1) } \\
\text { With D-STATCOM only }\end{array}$} & \multicolumn{3}{|c|}{$\begin{array}{c}\text { (Case-2) } \\
\text { With D-STATCOM and DG units }\end{array}$} \\
\hline & W1 & W2 & W3 & $\begin{array}{l}\text { T.P.L } \\
(\mathrm{kW})\end{array}$ & $\begin{array}{c}\text { Cost } \\
\text { function (Million \$) }\end{array}$ & D.B.V & $\begin{array}{l}\text { T.P.L } \\
(\mathrm{kW})\end{array}$ & $\begin{array}{l}\text { Cost function } \\
\text { (Million } \$ \text { ) }\end{array}$ & D.B.V \\
\hline 1 & 0.1 & 0.1 & 0.8 & 193.72 & 29.9647 & 1.9474 & 149.87 & 27.3156 & 1.7238 \\
\hline 2 & 0.1 & 0.8 & 0.1 & 193.72 & 29.2114 & 1.9827 & 149.87 & 27.1855 & 1.7894 \\
\hline 3 & 0.8 & 0.1 & 0.1 & 187.54 & 29.9647 & 1.9827 & 140.33 & 27.3156 & 1.7894 \\
\hline 4 & 0.5 & 0.3 & 0.2 & 189.27 & 29.5481 & 1.9711 & 142.79 & 27.2918 & 1.7622 \\
\hline 5 & 0.5 & 0.2 & 0.3 & 189.27 & 29.7948 & 1.9654 & 142.79 & 27.3043 & 1.7581 \\
\hline 6 & 0.3 & 0.5 & 0.2 & 191.11 & 29.3676 & 1.9711 & 144.34 & 27.2451 & 1.7622 \\
\hline 7 & 0.3 & 0.2 & 0.5 & 191.11 & 29.7948 & 1.9527 & 144.34 & 27.3043 & 1.7457 \\
\hline 8 & 0.2 & 0.5 & 0.3 & 192.47 & 29.3676 & 1.9654 & 146.77 & 27.2451 & 1.7581 \\
\hline 9 & 0.2 & 0.3 & 0.5 & 192.47 & 29.5481 & 1.9527 & 146.77 & 27.2918 & 1.7457 \\
\hline
\end{tabular}

The convergence characteristic of MPSO for single objective of minimization of power losses, minimization of cost function and minimization of deviation of bus voltage are shown in fig. 3 and fig. 4 for IEEE-33 and IEEE-69 bus systems respectively.

The results of MOMPSO for IEEE-33 and IEEE-69 bus system that gives the optimal sizes and power losses and deviation of bus voltage by considering two objective function in three combinations for different weight factors is given in tables 2 and 3, for three objective functions MOMPSO for different weight factors are given in tables 4 and 5.

\section{CONCLUSION}

In this paper, the optimal locations of DG units and DSTATCOM are found by sensitivity analysis and their optimal sizes are found by an algorithm based on multi objective modified particle swarm optimization (MPSO). The proposed algorithm has been tested on two test systems for single objective function, 3-combination of two objective functions and three objective functions for different weight factors and results are presented and analyzed. From these results it is observed that, including DG units and S-STATCOM with the distribution system optimally and operated with their optimal size will results in reasonable reduction of objective function values.

\section{REFERENCES}

[1] Rueda-Medina Augusto C, Franco John F, Rider Marcos J, PadilhaFeltrin Antonio, Romero Rubén. Mixed-integer linear programming approach for optimal type, size and allocation of distributed generation in radial distribution systems. Electr Power Syst Res 2013;97:133-43.
[2] Moradi MH, Abedini M. A combination of genetic algorithm and particle swarm optimization for optimal DG location and sizing in distribution systems. Electr Power Energy Syst 2012;34:66-74.

[3] Devi S, Geethanjali M. Application of modified bacterial foraging optimization algorithm for optimal placement and sizing of distributed generation. Expert Syst Appl 2014;41:2772-81.

[4] Singh SP, Rao AR. Optimal allocation of capacitors in distribution systems using particle swarm optimization. Electr Power Energy Syst 2012;43:1267-75.

[5] Hamouda Abdellatif, Sayah Samir. Optimal capacitors sizing in distribution feeders using heuristic search based node stabilityindices. Electr Power Energy Syst 2013;46:56-64.

[6] Kaur Damanjeet, Sharma Jaydev. Multiperiod shunt capacitor allocation in radial distribution systems. Electr Power Energy Syst 2013;52:247-53.

[7] Carpinelli G, Proto D, Noce C, Russo A, Varilone P. Optimal allocation of capacitors in unbalanced multi-converter distribution systems: a comparison of some fast techniques based on genetic algorithms. Electr Power Syst Res 2010;80:642-50.

[8] Tabatabaei SM, Vahidi B. Bacterial foraging solution based fuzzy logic decision for optimal capacitor allocation in radial distribution system. Electr Power Syst Res 2011;81:1045-50.

[9] Abul'Wafa Ahmed R. Optimal capacitor allocation in radial distribution systems for loss reduction: a two stage method. Electr Power Syst Res 2013;95:168-74.

[10] Hosseini Mehdi, Shayanfar Heidar Ali, Fotuhi Firuzabad Mahmoud. Modelling of series and shunt distribution FACTS devices in distribution systems load flow. J Electr Sys 2008;4-4:1-12.

[11] Valderrábano Antonio, Ramirez Juan M. DStatCom regulation by a fuzzy segmented PI controller. Electr Power Syst Res 2010;80:70715 .

[12] Teng Jen-Hao. A direct approach for distribution system load flow solutions. IEEE Trans Evolu Comput 2003;18:882-7.

[13] Agalgaonkar P, et al. Placement and penetration of distributed generation under standard market design. International Journal on Emerg Electr Power Syst 2004;1(1) 